\title{
Thử nghiệm cảnh báo dông cho khu vực Việt Nam bằng phương pháp kết hợp sản phẩm ra đa thời tiết và dữ liệu sét
}

\author{
Phùng Kiến Quốc ${ }^{1^{*}}$, Trần Tùng Lâm ${ }^{1}$, Đỗ Thị Ánh Huyền ${ }^{1}$ \\ ${ }^{1}$ Đài Khí tượng cao không; kienquocamo@gmail.com; lamtrant61@gmail.com; \\ anhhuyen1998.n@gmail.com
}

* Tác giả liên hệ: kienquocamo@gmail.com; Tel.: +84-989123047

Ban Biên tập nhận bài: 1/2/2021; Ngày phản biện xong: 8/3/2021; Ngày đăng bài: $25 / 3 / 2021$

Tóm tắt: Dông là nguyên nhân dẫn đến sự hình thành và phát triển nhiều hiện tượng thời tiết nguy hiểm và có thể gây thiệt hại nghiêm trọng về tài sản và tính mạng con người. Nghiên cứu này trình bày phương pháp cảnh báo dông dựa trên dữ liệu ra đa thời tiết kết hợp với dữ liệu của các trạm định vị sét tại Việt Nam. Kết quả nghiên cứu cho thấy các chỉ tiêu được xem xét khả năng có dông đối với các sản phẩm của ra đa là: $\mathrm{HMAX} \geq 10 \mathrm{~km}, \mathrm{ETOPS}$ $\geq 7 \mathrm{~km}, \mathrm{CMAX} \geq 35 \mathrm{dBZ}$ và CAPPI $2 \geq 40 \mathrm{dBZ}$. Nếu chỉ sử dụng một trong bốn điều kiện trên trong trường hợp không có sét thì đó là chỉ số chưa tốt và chưa thể sử dụng để xác định dông. Nếu sử dụng hai trong bốn điều kiện đó và không có sét thì đây cũng có thể là một chỉ số để xác định dông nhưng độ chính xác khoảng 72,08\%. Kết quả cũng chỉ ra rằng việc kết hợp các tiêu chí trên (HMAX $\geq 10 \mathrm{~km}$, ETOPS $\geq 7 \mathrm{~km}$, CMAX $\geq 35 \mathrm{dBZ}$, CAPPI $2 \geq 40$ $\mathrm{dBZ}$ ) cùng dữ liệu sét có thể là một chỉ số để xác định dông đạt độ chính xác cao lên đến $86,25 \%$.

Từ khóa: Dông; Ra đa thời tiết; Cảnh báo; Định vị sét.

\section{Mở đầu}

Dông được hiểu là hiện tượng khí tượng phức hợp gồm chớp và kèm theo sấm do đối lưu rất mạnh trong khí quyển gây ra. Trong cơn dông cũng thường kèm theo gió mạnh, mưa rào, sấm sét dữ dội, thậm chí cả mưa đá, vòi rồng (ở vùng vĩ độ cao có khi còn có cả tuyết rơi). Nghiên cứu về sét trở nên phổ biến rộng rãi vào cuối thế kỷ 19. [1] giải thích rằng sét đã được quan sát thấy trong không khí, các đám mây đối lưu, các đám mây tầng, các đám mây không tạo ra mưa và phần lớn sét thường xảy ra trong các cơn dông.

Trong lĩnh vực khí tượng thủy văn, dông là một trong những hiện tượng thời tiết nguy hiểm được đặc biệt quan tâm do có tác động không nhỏ đển đời sống con người. Theo thống kê của các tổ chức hàng không dân dụng, các vụ tai nạn trực tiếp và gián tiếp do dông sét chiếm hơn $50 \%$ tổng số các vụ tai nạn bay do các nguyển nhân khí tượng khác [2]. Nâng cao khả năng nhận biết mưa dông có ý nghĩa quan trọng đối với công tác dự báo, cảnh báo sớm và giảm thiểu rủi ro, thiệt hại do thiên tai gây ra. Bên cạnh vệ tinh khí tượng và thiết bị định vị sét, ra đa thời tiết hiện đại với độ phân giải cao cả về không gian và thời gian chính là phương tiện hữu ích để phát hiện và cảnh báo dông theo thời gian thực hiệu quả.

Trên thế giới đã có nhiều công trình nghiên cứu sử dụng số liệu ra đa trong việc giám sát, phát hiện dông, sét [3-7]. Có nhiều loại chỉ tiêu phát hiện dông bằng phản hồi vô tuyến ra đa (PHVT). Các chỉ tiêu này được xây dựng dựa trên những quan điểm khác nhau về bản chất vật lý của hiện tượng dông. Trong vài thập kỷ trước đây, nhiều nghiên cứu về dông được phát triển dựa trên phân ngưỡng PHVT, ví dụ, [3] đã đề xuất thuật toán TITAN (Thunderstorm 
Identification, Tracking, Analysis and Nowcasting) để phát hiện các cơn dông bão đối lưu với ngưỡng PHVT duy nhất là $30 \mathrm{dBZ}$. Năm 2009, thuật toán TITAN đã được cải tiến với tên gọi ETITAN sử dụng đa ngưỡng để phát hiện bão đối lưu [4]. Cũng vào thời gian đó, trong nghiên cứu của mình, [5] đã lấy ngưỡng $44 \mathrm{dBZ}$ để phát hiện các ổ mây đối lưu. Theo các nghiên cứu [6-7], hoạt động của sét có liên quan chặt chẽ với các quá trình động lực học và vi vật lý của các đám mây dông và sét được coi là một chỉ số tuyệt vời để nghiên cứu cường độ của các đám mây dông mạnh. Thêm vào đó, các mối liên hệ giữa sét và đặc điểm cấu trúc PHVT của đám mây dông chẳng hạn như độ cao đỉnh PHVT (ETOPS) và PHVT cực đại (CMAX) ở các độ cao khác nhau cũng được đề cập [8-10]. [11] đã chỉ ra mối quan hệ xác thực giữa PHVT ra đa và sét trong hệ thống đối lưu quy mô vừa như dông đa ổ, dông siêu ổ, đường tố và mưa đá. Một số nghiên cứu khác cũng được thực hiện về ứng dụng mối quan hệ giữa các tham số ra đa và sét từ mây xuống đất $(\mathrm{CG})$. [12] cho rằng tương quan giữa các thông số ra đa và sét $C G$ có thể được sử dụng để dự báo các đặc tính động lực học, vi vật lý và điện của các cơn dông. [13] nhận thấy trong cơn dông, tần số sét CG có tương quan âm với vùng phản hồi khi PHVT trên $65 \mathrm{dBZ}$. [14-15] lại cho rằng PHVT khối trên $40 \mathrm{dBZ}$ có tương quan tốt với sét $C G$. Khi nghiên cứu về đường tố ở khu vực Tây Phi, [16] đã phát hiện ra các hoạt động của sét tương ứng tốt với cường độ PHVT ra đa. Trong khi đó, [17] lại tập trung vào mối quan hệ giữa tần số sét của một hệ thống đối lưu nhỏ và độ cao PHVT của ra đa và nhận thấy rằng hầu hết các tia chớp xảy ra ở độ cao 3-6 km hoặc 7-10 km. Những năm gần đây, dữ liệu sét đã trở thành nguồn dữ liệu bổ sung quan trọng trong các nghiên cứu về các sự kiện đối lưu nguy hiểm [18-19]. Sự kết hợp giữa sét và các thông số thu được từ ra đa có thể đem lại những hiểu biết mới, quan trọng trong việc xác định đặc điểm của cơn dông và cảnh báo mọi người về các hiện tượng thời tiết khắc nghiệt sắp xảy ra [20]. Khi được kêt hợp lại, hai bộ dữ liệu này đã tạo thành một cơ sở vững chắc cho việc dự báo thời tiết đổi lưu thời hạn ngắn.

Việc ứng dụng dữ liệu ra đa thời tiết để đưa ra các chỉ tiêu cảnh báo mưa dông trong các nghiên cứu ở Việt Nam đã được một số tác giả trong nước thực hiện và đạt được những kết quả nhất định. [21] đã nghiên cứu sử dụng thông tin ra đa thời tiết DWSR-2500C của ra đa Nhà Bè phục vụ cảnh báo và theo dõi mưa, dông. Ngoài kết quả phân loại được các loại hình thế gây mưa, công trình trên còn xây dựng được các chỉ tiêu cảnh báo mưa và dông cho khu vực thành phố Hồ Chí Minh và vùng lân cận. [22-23] đã nghiên cứu sử dụng thông tin ra đa thời tiết phục vụ theo dõi, cảnh báo mưa, dông và bão và nghiên cứu xây dựng quy trình theo dõi các hiện tượng thời tiết nguy hiểm: tố, lốc, mưa đá, mưa lớn cục bộ bằng hệ thống ra đa thời tiết TRS-2730. Bên cạnh việc xác định được các đặc điểm PHVT liên quan đến các hiện tượng thời tiết nguy hiểm cục bộ để làm cơ sở cho việc phát hiện và theo dõi các hiện tượng này bằng ra đa TRS-2730, tác giả còn xây dựng được các chỉ tiêu nhận biết dông thông qua giá trị PHVT và một số kết quả khác. Các chỉ tiêu xây dựng cho 03 ra đa TRS-2730 đã giúp cho các quan trắc viên và dự báo viên có được công cụ hiệu quả để xác định các hiện tượng thời tiết nguy hiểm như dông, tố lốc, mưa đá và đưa ra các cảnh báo, dự báo mưa trong vùng hoạt động của ra đa. Tuy nhiên hiện nay, các ra đa thế hệ cũ trên đã không còn hoạt động và được thay thế bằng các hệ thống ra đa tiên tiến khác. Tính đến thời điểm tháng 4 năm 2020 , mạng lưới ra đa thời tiết ở Việt Nam (Hình 1 ) đã được nâng cấp và xây dựng mới bao gồm 10 trạm với các hệ thống ra đa phân cực đơn và phân cực đôi hiện đại nhằm cải thiện chất lượng dự báo các hiện tượng thời tiết nguy hiểm cũng như dự báo định lượng mưa. Cùng với hệ thống trạm ra đa thời tiết, mạng lưới 18 trạm định vị sét (Hình 2) có độ phân giải không gian cao từ 150-200 km và thời gian quan trắc liên tục sẽ là những thành phần thiết yếu của hệ thống dự báo hiện đại, là những kênh thông tin dữ liệu tin cậy cần thiết cho dự báo thời gian thực và cảnh báo sớm các hiện tượng thời tiết khắc nghiệt.

Nghiên cứu này sẽ trình bày phương pháp cảnh báo dông bằng cách sử dụng dữ liệu ra đa thời tiết kết hợp với số liệu định vị sét cho khu vực Việt Nam. Khác với các công trình nghiên cứu trong nước trước đó, phương pháp cảnh báo dông kết hợp này có ưu điểm là sử dụng hầu 
hết các sản phẩm thứ cấp đặc trưng của hệ thống ra đa thời tiết để cảnh báo dông. Hơn nữa, việc kết hợp với dữ liệu sét để khẳng định xác suất, mức độ chính xác của việc cảnh báo dông đã làm rõ hơn nữa vai trò của hệ thống quan trắc ra đa thời tiết, định vị sét trong công tác dự báo, cảnh báo các hiện tượng thời tiết liên quan đến dông sét tại Việt Nam. Đây cũng có thể xem như là một tiêu chí tham khảo cho các dự báo viên khi thực hiện công tác dự báo, cảnh báo dông sử dụng các nguồn dữ liệu quan trắc trên cao.

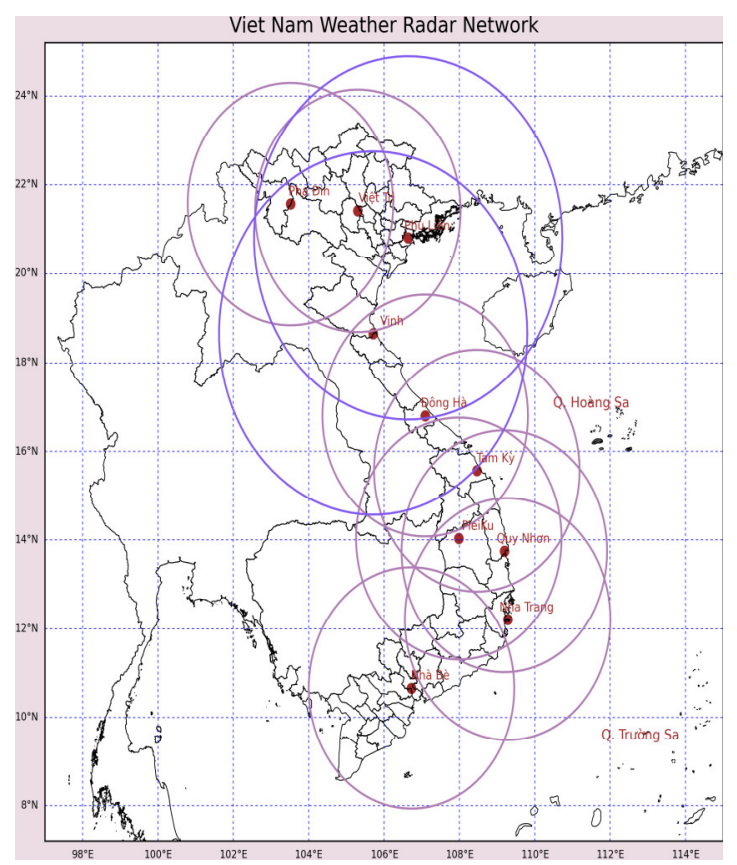

Hình 1. Mạng lưới trạm ra đa thời tiết tại Việt Nam (màu xanh: ra đa phân cực đơn; màu tím: ra đa phân cực đôi).

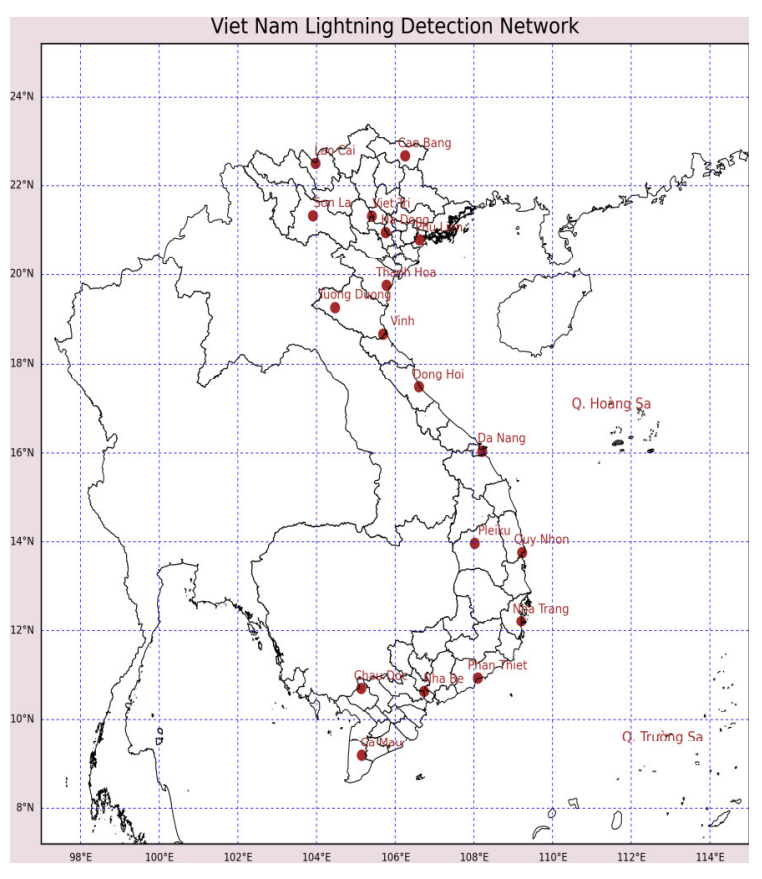

Hình 2. Mạng lưới trạm định vị sét tại Việt Nam.

\section{Phương pháp nghiên cứu và số liệu}

\subsection{Các nguồn số liệu}

Nguồn dữ liệu sử dụng trong nghiên cứu này bao gồm các nguồn dữ liệu chính là dữ liệu của các trạm ra đa thời tiết và dữ liệu của 18 trạm định vị sét của Việt Nam. Các dữ liệu này đều được kiểm tra chất lượng và lưu trữ tại máy chủ của Đài Khí tượng cao không. Tập dữ liệu ra đa gốc sẽ dùng để tạo ra các sản phẩm thứ cấp: ETOPS (Độ cao đỉnh PHVT), HMAX (độ cao PHVT cực đại), CMAX (PHVT cực đại), CAPPI2 (PHVT ở độ cao $2 \mathrm{~km}$ ) để đưa vào tính toán.

Để xác minh được thời điểm xảy ra dông, số liệu sẽ được tham chiếu từ các trạm quan trắc khí tượng bề mặt. Dựa trên tương quan về khoảng cách, danh sách các trạm khí tượng bề mặt và trạm ra đa thời tiết tương ứng được lựa chọn trong Bảng 1 . Toàn bộ chuỗi số liệu được thu thập để tính toán trong 5 tháng đầu năm 2020 (từ 1/1/2020 đến 20/5/2020).

Bảng 1. Danh sách các trạm ra đa thời tiết và trạm quan trắc khí tượng bề mặt.

\begin{tabular}{cccc}
\hline STT & $\begin{array}{c}\text { Trạm ra } \\
\text { đa thời tiết }\end{array}$ & $\begin{array}{c}\text { Trạm khí } \\
\text { tượng bề }\end{array}$ & $\begin{array}{c}\text { Khoảng } \\
\text { cách }\end{array}$ \\
\hline 1 & Pha Đin & Sơn La & \\
2 & Phù Liễn & Phù Liễn & $\leq 40 \mathrm{~km}$ \\
3 & Vinh & Vinh & \\
\hline
\end{tabular}




\begin{tabular}{cccc}
\hline STT & $\begin{array}{c}\text { Trạm ra } \\
\text { da thời tiết }\end{array}$ & $\begin{array}{c}\text { Trạm khí } \\
\text { tượng bề }\end{array}$ & $\begin{array}{c}\text { Khoảng } \\
\text { cách }\end{array}$ \\
\hline 4 & Tam Kỳ & Đà Nẵng & \\
5 & Đông Hà & Đồng Hới & \\
6 & Quy Nhơn & Quy Nhơn & \\
7 & Pleiku & Pleiku & \\
8 & Nhà Bè & Nhà Bè \\
9 & Việt Trì & Việt Trì \\
10 & Nha Trang & Nha Trang & \\
\hline
\end{tabular}

\subsection{Cách xác định ngương xuất hiện dông}

Nếu chỉ căn cứ vào một sản phẩm ETOPS hoặc CMAX hoặc HMAX hoặc CAPPI thì chưa thể kết luận được là có dông hay không, hay mức độ nguy hiểm của cơn dông này mang lại. Vì vậy để tăng độ chính xác phát hiện dông cần phải kết hợp thêm các yếu tố khác. Trong nghiên cứu này, yếu tố sét sẽ được đưa vào để tìm ra được ngưỡng tốt nhất đối với các sản phẩm kể trên.

Cách xác định ngưỡng xuất hiện dông được thực hiện theo các bước sau: (1) Xác định thời điểm xảy ra dông dựa vào quan trắc tại các trạm khí tượng bề mặt; (2) Trích xuất các sản phẩm ETOPS, CMAX, HMAX, CAPPI2 tại thời điểm có dông; (3) Trích xuất dữ liệu sét trong vòng bán kính $40 \mathrm{~km}$ tính từ trạm khí tượng bề mặt; (4) Xác định tương quan giữa sét và các dữ liệu ở bước 2 .

Với bộ số liệu 5 tháng đầu năm 2020, tổng số các đợt dông thu thập được trong vòng bán kính quét của các ra đa là 278 đợt. Trong đó trạm ra đa Nhà Bè là nơi quan trắc được nhiều dông nhất trong giai đoạn này (61 đợt). Dựa vào bộ số liệu này đã đưa ra được bộ chỉ tiêu về các loại sản phẩm ra đa như ETOPS, CMAX, HMAX, CAPPI2 với các giá trị ngưỡng cụ thể được sử dụng kết hợp với số liệu định vị sét để đưa ra phương pháp cảnh báo dông kết hợp được trình bày trong phần 3 . Kết quả phân loại ngưỡng xuất hiện dông theo cách xác định trên được đưa ra sơ bộ như sau:

Bảng 2. Ngưỡng của các chỉ số xuất hiện dông.

\begin{tabular}{cccc}
\hline \multirow{2}{*}{ Chỉ số } & Ngưỡng & \multicolumn{2}{c}{ Xác suất có dông (\%) } \\
\cline { 3 - 4 } & & Có sét & Không có sét \\
\hline ETOPS & $7 \mathrm{~km}$ & 100 & 50 \\
CMAX & $35 \mathrm{dBZ}$ & $85-100$ & $50-70$ \\
HMAX & $10 \mathrm{~km}$ & 100 & $50-70$ \\
CAPPI2 & $40 \mathrm{dBZ}$ & 100 & $50-70$ \\
\hline
\end{tabular}

Bảng 2 cho thấy các chỉ tiêu được xem xét khả năng có dông đối với các sản phẩm của ra đa là: $\operatorname{HMAX} \geq 10 \mathrm{~km}, \mathrm{ETOPS} \geq 7 \mathrm{~km}, \mathrm{CMAX} \geq 35 \mathrm{dBZ}$ và CAPPI $2 \geq 40 \mathrm{dBZ}$ nếu các chỉ số đạt ngưỡng mà kèm theo sét thì xác suất xuất hiện dông có thể lên tới $100 \%$, trong khi nếu không có sét thì xác suất xuất hiện dông vào khoảng 50-70\%.

\section{Kết quả thử nghiệm phương pháp cảnh báo dông kết hợp}

Nội dung phần này sẽ trình bày phương pháp cảnh báo dông kết hợp giữa dữ liệu ra đa và dữ liệu định vị sét dựa trên các chỉ tiêu đã xác định được ở phần trên. Sơ đồ thuật toán được thể hiện trong Hình 3. 


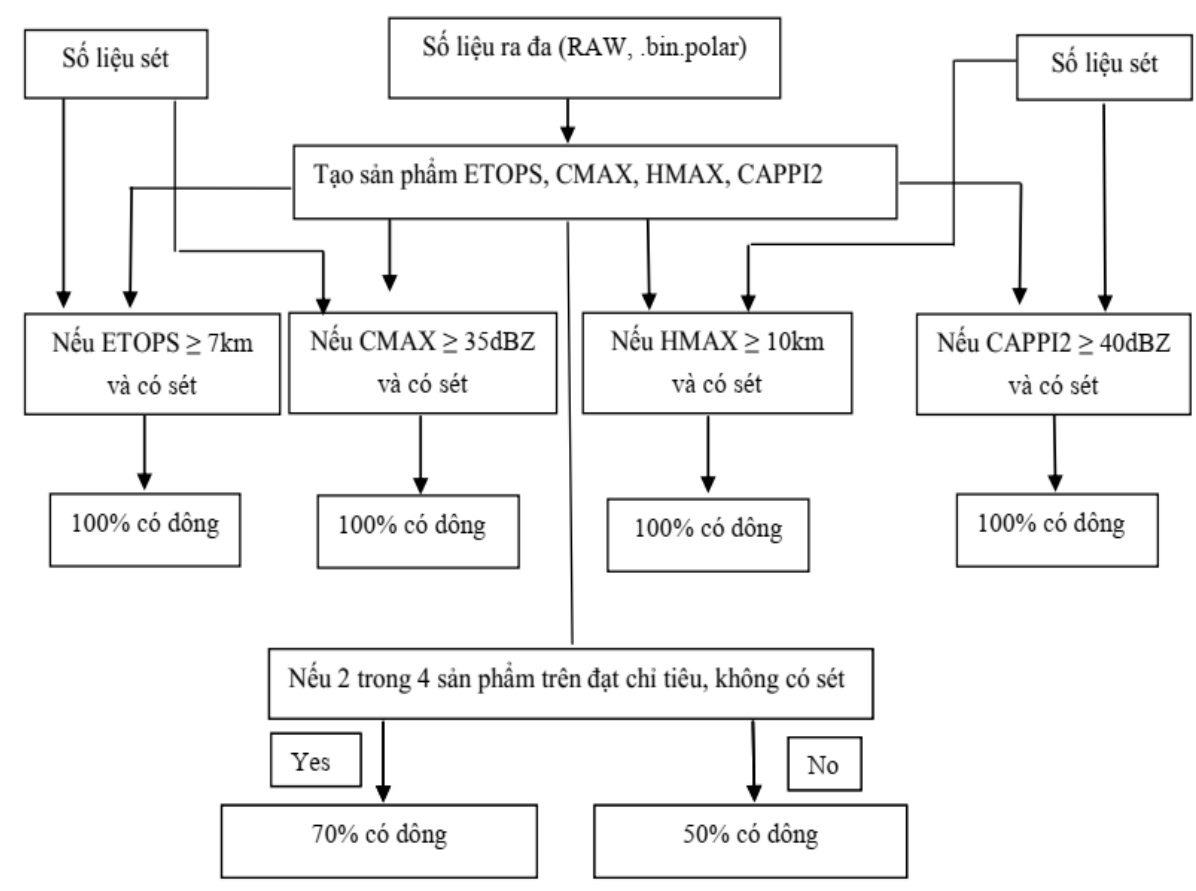

Hình 3. Sơ đồ thuật toán phương pháp cảnh báo dông kết hợp.

Dưới đây là các bước thực hiện: Bước 1: Trích xuất các sản phẩm ETOPS, CMAX, HMAX, CAPPI2 từ dữ liệu ra đa gốc; Bước 2: Trích xuất dữ liệu định vị sét trong vòng bán kính $40 \mathrm{~km}$, tâm vòng tròn là điểm lưới ra đa ứng với các sản phẩm ETOPS, CMAX, HMAX và CAPPI2; Bước 3: Xác định khả năng xuất hiện dông và biểu diễn trên bản đồ phân loại màu.

Thuật toán được áp dụng thử nghiệm cảnh báo dông cho ngày $28 / 5$ và ngày $29 / 5$ năm 2020. Kết quả thử nghiệm được thể hiện qua bản đồ phân loại màu trong Hình 4 và Hình 5 tại các thời điểm $00 \mathrm{Z}, 06 \mathrm{Z}, 12 \mathrm{Z}$ và $18 \mathrm{Z}$. Trong đó, những vùng có màu xanh biểu thị khả năng xuất hiện dông là $50 \%$, màu vàng biểu thị khả năng xuất hiện dông là $70 \%$ và màu đỏ biểu thị khả năng xuất hiện dông là $100 \%$.

Để đánh giá độ chính xác khả năng xuất hiện dông, chúng tôi đã kiểm chứng kết quả trên bản đồ phân loại màu với số liệu dông từ các trạm quan trắc khí tượng bề mặt trong 2 ngày liên tiếp từ lúc $00 Z$ ngày $28 / 5 / 2020$ đến lúc $18 Z$ ngày $29 / 5 / 2020$, với mỗi ốp quan trắc cách nhau 6 giờ. Dưới đây là kết quả của việc đánh giá:

Bảng 3. Độ chính xác của phương pháp cảnh báo dông kết hợp trong ngày 28/5/2020 và ngày 29/5/2020.

\begin{tabular}{ccccccc}
\hline \multirow{2}{*}{ Xác suất } & \multirow{2}{*}{ Ngày } & \multicolumn{5}{c}{ Độ chính xác (\%) } \\
\cline { 3 - 7 } & & $\mathbf{0 0 Z}$ & $\mathbf{0 6 Z}$ & $\mathbf{1 2 Z}$ & $\mathbf{1 8 Z}$ & Trung bình \\
\hline \multirow{2}{*}{$50 \%$ có dông } & $28 / 5 / 2020$ & 45,45 & 29,41 & 60,6 & 40 & 48,81 \\
& $29 / 5 / 2020$ & 40 & 40 & 75 & 60 & \\
\multirow{2}{*}{$70 \%$ có dông } & $28 / 5 / 2020$ & 66,67 & 60 & 100 & 100 & 72,08 \\
& $29 / 5 / 2020$ & 50 & 50 & 100 & 50 & \\
\multirow{2}{*}{$100 \%$ có dông } & $28 / 5 / 2020$ & 50 & 40 & 100 & 100 & 86,25 \\
& $29 / 5 / 2020$ & 100 & 100 & 100 & 100 & \\
\hline
\end{tabular}

Như vậy, trong trường hợp thử nghiệm này có thể cho thấy xác suất xảy ra dông $50 \%$ có độ chính xác thấp nhất; xác suất xảy ra dông $70 \%$ có độ chính xác vào khoảng $72,08 \%$; trong khi xác suất xảy ra dông $100 \%$ có độ chính xác cao nhất là $86,25 \%$. 


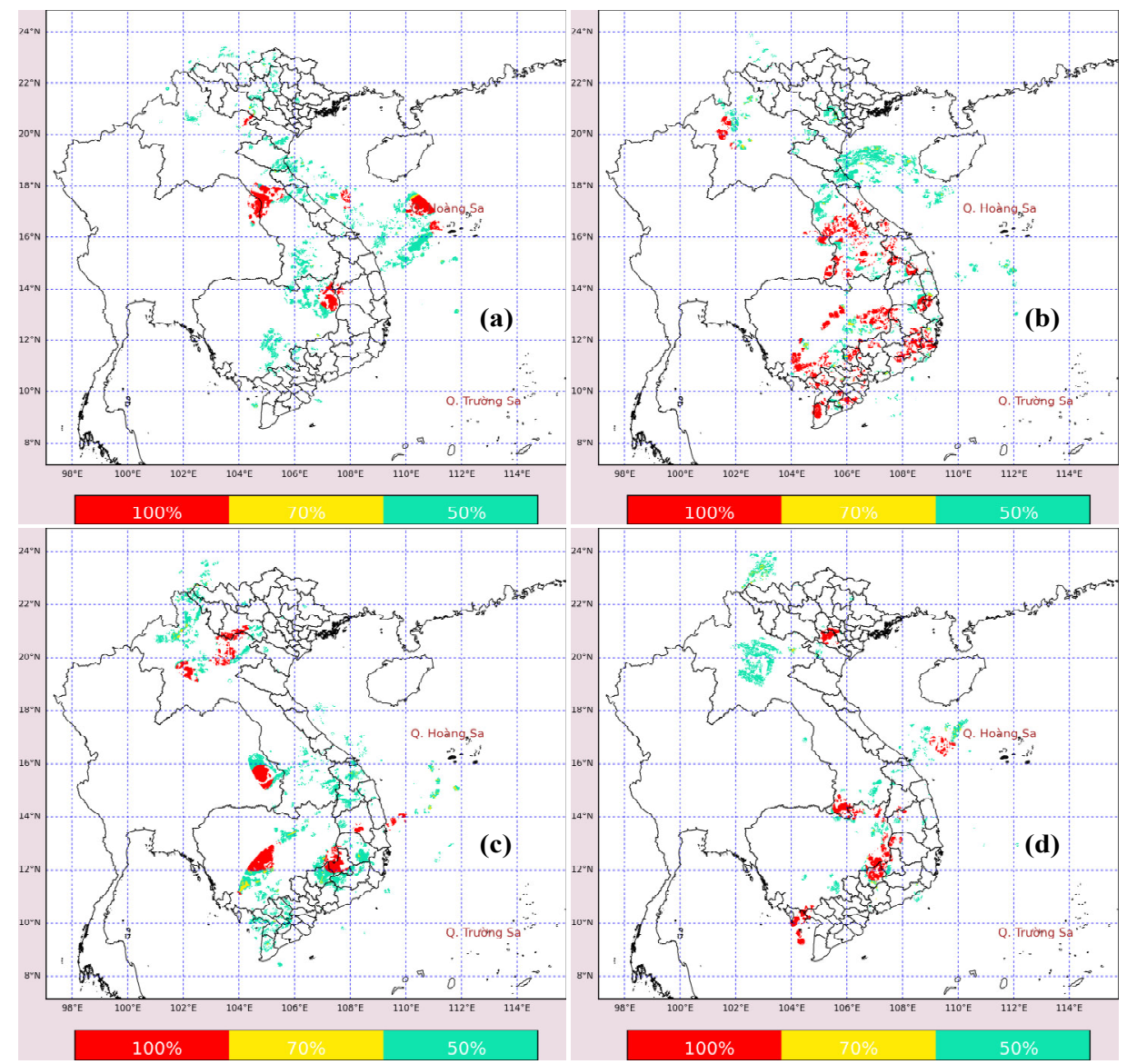

Hình 4. Bản đồ cảnh báo dông bằng phương pháp kết hợp lúc: (a) $00 \mathrm{Z}$, (b) $06 \mathrm{Z}$, (c) $12 \mathrm{Z}$ và (d) $18 \mathrm{Z}$ ngày $28 / 5 / 2020$.

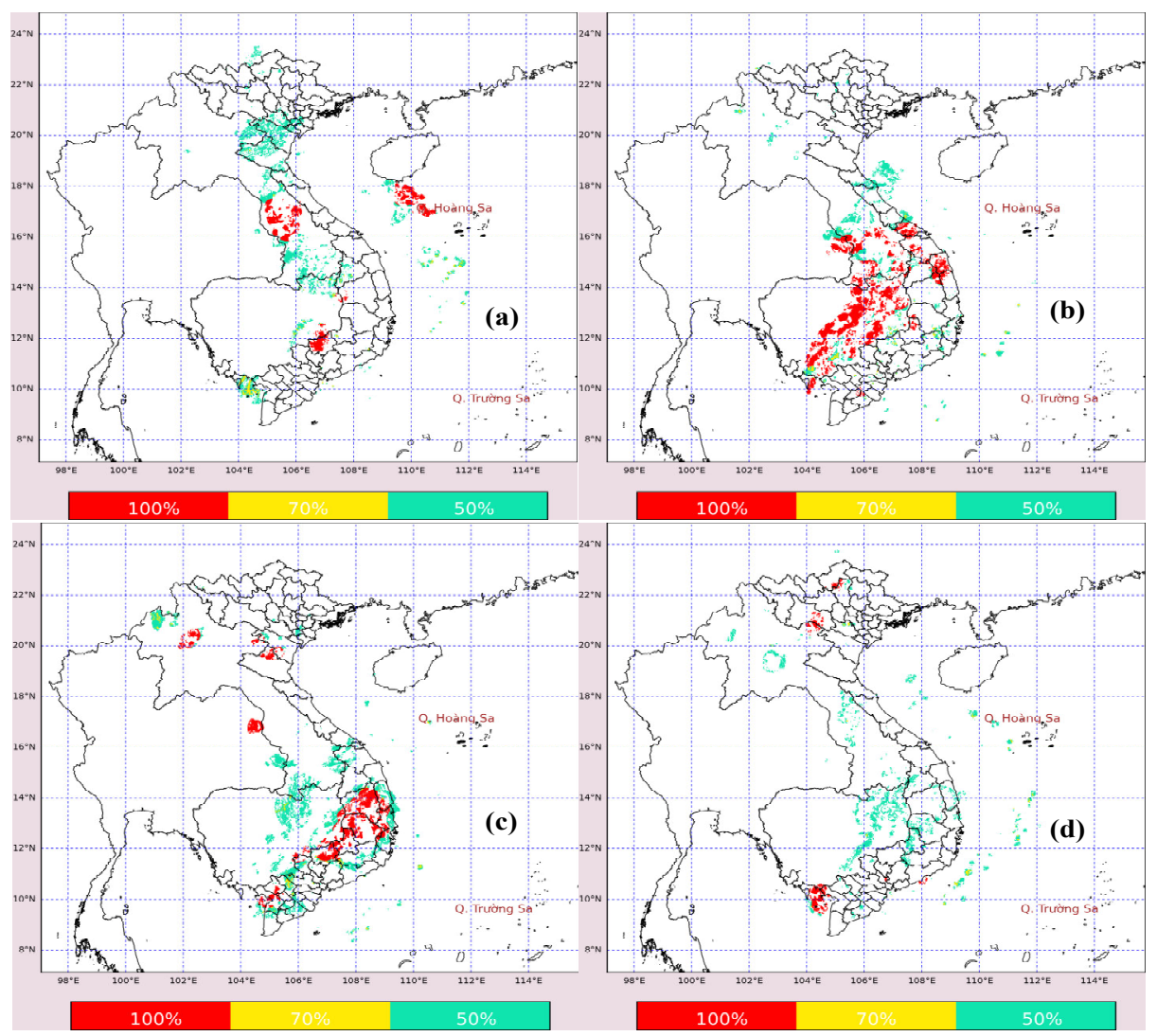

Hình 5. Bản đồ cảnh báo dông bằng phương pháp kết hợp lúc: (a) $00 \mathrm{Z}$, (b) $06 \mathrm{Z}$, (c) $12 \mathrm{Z}$ và (d) $18 \mathrm{Z}$ ngày $29 / 5 / 2020$. 


\section{Kết luận}

Bài báo đã giới thiệu phương pháp cảnh báo dông kết hợp dựa trên số liệu ra đa thời tiết và định vị sét. Các kết quả ban đầu cho thấy các ngưỡng sản phẩm ra đa $H M A X \geq 10 \mathrm{~km}$, ETOPS $\geq 7 \mathrm{~km}, \mathrm{CMAX} \geq 35 \mathrm{dBZ}, \mathrm{CAPPI} 2 \geq 40 \mathrm{dBZ}$ kết hợp với dữ liệu sét có thể là một chỉ số để xác định dông đạt độ chính xác cao đến $86,25 \%$. Với trường hợp sử dụng hai trong bốn điều kiện $\mathrm{HMAX} \geq 10 \mathrm{~km}, \mathrm{ETOPS} \geq 7 \mathrm{~km}, \mathrm{CMAX} \geq 35 \mathrm{dBZ}, \mathrm{CAPPI} 2 \geq 40 \mathrm{dBZ}$ và không có sét cũng có thể là một chỉ số để cảnh báo dông nhưng độ chính xác thấp hơn. Trường hợp chỉ sử dụng một trong bốn điều kiện $H M A X \geq 10 \mathrm{~km}$, ETOPS $\geq 7 \mathrm{~km}, \mathrm{CMAX} \geq 35 \mathrm{dBZ}$, CAPPI $2 \geq 40 \mathrm{dBZ}$ và không có sét là chỉ số chưa tốt và chưa thể sử dụng để cảnh báo dông.

Để phương pháp đề cập trong bài báo này có thể ứng dụng vào nghiệp vụ dự báo, cảnh báo dông cần phải có thêm nhiều nghiên cứu chuyên sâu và với chuỗi số liệu dài hơn trong tương lai.

Đóng góp của tác giả: Xây dựng ý tưởng nghiên cứu: P.K.Q.; Lựa chọn phương pháp nghiên cứu: P.K.Q. Xử lý số liệu: T.T.L.; Phân tích mẫu: P.K.Q., D.T.A.H.; Lấy mẫu: T.T.L., D.T.A.H. Viết bản thảo bài báo: P.K.Q. Chỉnh sửa bài báo: P.K.Q.

Lời cảm ơn: Tập thể tác giả trân trọng cảm ơn sự hỗ trợ của đề tài nghiên cứu khoa học cấp Bộ "Nghiên cứu xây dựng công cụ cảnh báo dông và định lượng mưa cho các khu vực ở Việt Nam trên cơ cở sử dụng số liệu ra đa thời tiết, định vị sét, ảnh mây vệ tinh Himawari và mưa bề mặt", mã số TNMT.2018.05.18.

Lời cam đoan: Tập thể tác giả cam đoan bài báo này là công trình nghiên cứu của tập thể tác giả, chưa được công bố ở đâu, không sao chép từ những nghiên cứu trước đây; không có sự tranh chấp lợi ích trong nhóm tác giả.

\section{Tài liệu tham khảo}

1. Uman, M.A. The Lightning Discharge. Dover Publications, Inc., Mineola, New York, 1987.

2. Wang, X.; Liao, R.; Li, J.; He, J.; Wang, G.; Xu, Z.; Wang, H. Thunderstorm identification algorithm research based on simulated airborne weather radar reflectivity data. J. Wirel. Commun. Networking 2020, 37. https://doi.org/10.1186/s13638-020-1651-6.

3. Dixon, M.; Wiener, G. TITAN: Thunderstorm identification, tracking, analysis, and nowcasting - A radar-based methodology. J. Atmos. Ocean. Technol. 1993, 10, 785-797.

4. Han, L.; Fu, S.; Zhao, L.; Zheng, Y.; Wang, H.; Lin, Y. 3D convective storm identification, tracking, and forecasting - An enhanced TITAN algorithm. J. Atmos. Ocean. Technol. 2009, 26, 719-732.

5. Kyznarová, H.; Novák, P. CELLTRACK - Convective cell tracking algorithm and its use for deriving life cycle characteristics. Atmos. Res. 2009, 93, 317-327.

6. Deierling, W.; Petersen, W.A. Total lightning activity as an indicator of updraft characteristics. J. Geophys. Res. 2008, 113, 280-288.

7. Qie, X.; Zhang, Y.; Yuan, T.; Zhang, Q.; Zhang, T.; Zhu, B.; Lü, W.; Ma, M.; Yang, J.; Zhou, Y.; Feng, G. A review of atmospheric electricity research in China. Adv. Atmos. Sci. 2015, 32, 169-191.

8. Cecil, D.J.; Goodman, S.J.; Boccippio, D.J.; Zipser, E.J.; Nesbitt, S.W. Three years of TRMM precipitation features. Part I: Radar, radiometric, and lightning characteristics. Mon.Weather Rev. 2005, 133, 543-566.

9. Pessi, A.T.; Businger, S. Relationships among lightning, precipitation, and hydrometeor characteristics over the North Pacific Ocean. J. Appl. Meteorol. Climatol. 2009, 48, 833-848. 
10. Ushio, T.; Heckman, S.J.; Boccippio, D.J.; Christian, H.J.; Kawasaki, Z.I. A survey of thunderstorm flash rates compared to cloud top height using TRMM satellite data. J. Geophys. Res. 2001, 106, 24089-24095. https://doi.org/10.1029/2001jd900233.

11. Carey, L.D.; Murphy, M.J.; McCormick, T.L.; Demetriades, N. Lightning location relative to storm structure in a leading-line, trailing-stratiform mesoscale convective system. J. Geophys. Res. 2005, 110, 1-23.

12. Steiger, S.M.; Orville, R.E.; Carey, L.D. Total lightning signatures of thunderstorm intensity over North Texas, Part II: Mesoscale convective systems. Mon. Weather Rev. 2007, 135, 3303-3324.

13. Knupp, K.R.; Peach, S.; Goodman, S. Variations in cloud-to-ground lightning characteristics among three adjacent tornadic supercell storms over the Tennesee valley region. Mon. Weather Rev. 2003, 131, 172-188.

14. Williams, E.R.; Boldi, B.; Matlin, A.; Weber, M.; Hodanish, S.; Sharp, D.; Goodman, S.; Raghavan, R.; Buechler, D. The behavior of total lightning activity in severe Florida thunderstorms. Atmos. Res. 1999, 51, 245-265.

15. Gilmore, M.S.; Wicker, L.J. Influences of the local environment on supercell cloud-to-ground lightning, radar characteristics, and severe weather on 2 June 1995. Mon. Weather Rev. 2002, 130, 2349-2472.

16. Cetrone, J.; Houze, R.A. Leading and trailing anvil clouds of West African squall lines. J. Atmos. Sci. 2011, 68, 1114-1123.

17. Lund, N.R.; MacGorman, D.R.; Schuur, T.J.; Krehbiel, W.R.; Hamlin, T.; Straka, J.M.; Biggerstaff, M.I. Relationships between lightning location and polarimetric radar signatures in a small mesoscale convective system. Mon. Weather Rev. 2009, 137, 4151-4170.

18. Shi, Z.; Tan, Y.; Liu, Y.; Liu, J.; Lin, X.T.; Wang, M.Y.; Luan, J. Effects of relative humidity on electrification and lightning discharges in thunderstorms. Terr. Atmos. Ocean. Sci. 2018, 29, 695-708.

19. Wu, F.; Cui, X.P.; Zhang, D.L.; Qiao, L. The relationship of lightning activity and short-duration rainfall events during warm seasons over the Beijing metropolitan region. Atmos. Res. 2017, 195, 31-43.

20. Steiger, S.M.; Orville, R.E.; Carey, L.D. Total lightning signatures of thunderstorm intensity over north Texas. Part I: Supercells. Mon. Wea. Rev. 2007, 135, 3281-3302.

21. Hào, N.T. Nghiên cứu sử dụng thông tin ra đa thời tiết DWSR-2500C trạm Nhà Bè phục vụ cảnh báo và theo dõi mưa. Báo cáo tổng kết đề tài nghiên cứu khoa học cấp Bộ, Bộ Tài nguyên và Môi Trường, 2011.

22. Sơn, T.D. Nghiên cứu sử dụng thông tin ra đa thời tiết phục vụ theo dõi, cảnh báo mưa, dông và bão. Báo cáo tổng kết đề tài nghiên cứu khoa học cấp Bộ, Bộ Tài nguyên và Môi Trường, 2007.

23. Sơn, T.D. Nghiên cứu xây dựng quy trình phát hiện theo dõi các hiện tượng thời tiết nguy hiểm: tố, lốc, mưa đá, mưa lớn cục bộ bằng hệ thống ra đa thời tiết TRS-2730. Báo cáo tổng kết đề tài cấp Bộ, Bộ Tài nguyên và Môi Trường, 2009. 


\title{
An experiment on thunderstorm warning by combining weather radar and lightning data in Vietnam
}

\author{
Phung Kien Quoc ${ }^{*}$, Tran Tung Lam ${ }^{1}$, Do Thi Anh Huyen ${ }^{1}$ \\ ${ }^{1}$ Aero Meteorological Observatory; kienquocamo@gmail.com; lamtrant61@gmail.com; \\ anhhuyen1998.n@gmail.com
}

\begin{abstract}
Thunderstorms are responsible for the development and formation of many severe weather phenomena and can cause serious damage to property and people. This study presents a thunderstorm warning method based on weather radar data combined with data of lightning detection stations in Vietnam. The results show that the considered thresholds that thunderstorms can occur for the weather radar products are: HMAX $\geq 10$ $\mathrm{km}$, ETOPS $\geq 7 \mathrm{~km}$, CMAX $\geq 35 \mathrm{dBZ}$, and CAPPI $2 \geq 40 \mathrm{dBZ}$. If only one of the four conditions above is used but no lightning is found, it is a not good index and should not be used to detect thunderstorms. In case, lightning is not found and two of the four conditions above are used and then this can use as an indicator to detect thunderstorms with the accuracy is about $72.08 \%$. The results also show that combining the above conditions (HMAX $\geq 10 \mathrm{~km}$, ETOPS $\geq 7 \mathrm{~km}, \mathrm{CMAX} \geq 35 \mathrm{dBZ}$, CAPPI $2 \geq 40 \mathrm{dBZ}$ ) with lightning data can be a good indicator to detect thunderstorms with high accuracy up to $86.25 \%$.
\end{abstract}

Keywords: Thunderstorms; Weather radar; Warnings; Lightning. 